The Corporation maintains close touch with the East African Agricultural and Forestry Research Organization and with the East African Tsetse and Trypanosomiasis Research and Reclamation Organization, as well as with departments of the Tanganyika Government and other bodies; but the work of the Scientific Department is presented on a regional basis in what forms the longest chapter of the report. Among some points of interest are the slight increase in plant population and the big increase in yield obtained in experiments on the control of weeds in maize with 'Fernoxone' at Urambo; the absence of any significant increase in yield of soys bean and maize on deep placement of triple phosphate fertilizer although the standard method of placing fertilizer gave highly significant increase; the identification in South Tanganyika of the maize rust Puccinia polysora Underw.; and the continued trials and experiments on the development and improvement of agricultural machinery. Soil fertility studies were restricted to maize, and little progress is reported in the determination of the phosphate status of soils by chemical tests.

\section{METEORIC PARTICLES IN THE ATMOSPHERE}

$\mathrm{Z}^{\mathrm{s}}$

DENEK SVESTKA, Astronomical Institute of the Czechoslovak Academy of Sciences, Ondřejov, has a paper in Bulletin of the Astronomical Institutes of Czechoslovalia (5, No. 5; Sept. 1, 1954), in which he criticizes F. Link's theory of the fall and absorption influence of meteoritic particles in the atmosphere. This theory has been explained in some of the B.A.C. issues over several years, and the time of fall $T$ in seconds through $100 \mathrm{~km}$. may be expressed by Link's approximate formula:

$$
\log _{10} T=C-1.5 \log _{10} \rho
$$

where $C=1.4$ for metallic particles and 1.6 for stony particles, the radius of the particles in all cases being $p$. According to this formula, the time of fall of 30-100 days would correspond to particles the diameters of which in the limit would conform with the relation $4 \mu<2 \rho<14 \mu$. From a study of the absorption influence of particles of different diameters Link also constructed an empirical formula for the number $n$ of particles of iron and silicates of different sizes :

$$
\log _{10} n=\text { constant }-600 p
$$

and making use of other data, concluded that the absorption in a layer of meteoric dust is caused predominantly by particles with diameters from $2 \mu$ to $6 \mu$.

Svestka has now examined Link's assumptions and deductions and concludes that the latter are inaccurate in many cases. Observations of absorption effects of a dust-layer in the atmosphere during lunar eclipses can be satisfied only when the optical thickness of the layer is equal to 0.01 as a minimum. A table gives for different values of $\rho$ the minimum possible time of fall for which the above optical thickness is assumed, and also the maximum quantity of meteoric matter falling on the earth, which, it is shown, cannot exceed $5 \times 10^{-14} \mathrm{gm} . \mathrm{cm}^{-2}$ sec.-1, and proves that it is quite impossible-from the optical point of view-that the observed absorption could be caused by particles larger than $1 \mu$. Link's theoretical conclusions were based on Thomsen's results of collections of atmospheric iron particles, the diameters of which ranged from $10 \mu$ to $80 \mu$; but there is very strong evidence from the collection of similar particles in the industrial country of Jena that the meteoritic nature of Thomsen's particles must be open to considerable doubt. It seems probable that meteoric dust is formed by much smaller particles of the order of $10^{-5}-10^{-6} \mathrm{~cm}$., and it is suggested that a study of the sky-light polarization, during and after the activity of strong meteor showers, might provide a decisive answer to the problem under investigation.

\section{THE EARTH'S EXTERIOR ATMOSPHERE AND THE COUNTERGLOW}

TNDER this title, the Canadian Defence Research Board has published a second augmented edition of material prepared by E. R. Hope*. In the main this consists of Mr. Hope's translations of recent Russian papers (two more than the first edition) of very great interest concerning observations and theories about the outermost atmosphere of the earth.

The Russian astronomers, Astapovich, Fesenkov, Divari and Karimov, have a particular claim to our attention, for they enjoy in some parts of their country a clarity of the sky which is unrivalled and which is a great asset to the observations concerning the outermost atmosphere and the counterglow. Their revolutionary theories are based in part on new observational discoveries, and their speculations make good use of all the knowledge there is on the subject. They establish that the observational material is in accord with the suggestion that a gaseous tail stretches away from the earth, resembling the tail of a comet, in the direction opposite to that of the sun. They do not suggest that the processes responsible for the heating of the outermost atmosphere or for the acceleration of the gas spraying off in the tail are at all understood.

The translator's foreword of twenty-six pages aims at reviewing the entire subject in a critical manner, and at establishing the relation between these outer atmosphere researches and those connected with magnetic and auroral effects. Much of this could come under severe criticism, and one suspects that most of the authors mentioned would disagree with the arguments presented that oppose their points of view, but equally with those that are in their favour. Those who are concerned with these subjects will have to go over the literature and the arguments for themselves, anyway; and those who would appreciate a passing acquaintance cannot be advised to gain it here, for they are unlikely to appreciate that another review article might, with equal justification, reverse very many of the arguments.

The translations of the Russian papers read well, and make a valuable contribution to the literature accessible to most Western astronomers and to those concerned with upper atmosphere research.

\section{T. GOLD}

* The Earth's Exterior Atmosphere and the Counterglow: The Counterglow as Related to Modern Geophysical Theories, with Seven Recent Russian papers. Collected and translated by E. R. Hope. Board (Defence Scientifle Information Service), 1954.) 